\title{
Exercise Prescription: Practices of Healthcare Professionals in Hospital Setting, Kenya
}

\author{
Oloo Micky Olutende ${ }^{1, *}$, Peter Wisiuba Bukhala ${ }^{1}$, Bernard Wesonga ${ }^{2}$ \\ ${ }^{1}$ Department of Health Promotion and Sports Science, Masinde Muliro University of Science and Technology \\ ${ }^{2}$ School of Medicine, Masinde Muliro University of Science and Technology \\ *Corresponding author: micky.oloo.mf@gmail.com
}

\begin{abstract}
Physical inactivity is a serious epidemic that affects one's health and there's evidence that exercise can improve quality of life and health. The healthcare setting has been recognized as an appropriate and promising venue for counseling and prescribing physical activity to increase activity index of the population. An exercise prescription from a healthcare professional will remind the patient that physical activity is part of their treatment plan and should be adhered to with the same diligence with which their medication is taken. However, limited research on the topic suggests that many healthcare professionals are not incorporating exercise into treatment, and many lack the confidence to do so. The purpose of this study was to evaluate current exercise prescription trends among practicing healthcare professionals in Kakamega County, Kenya. A cross-sectional study was carried out in public health facilities in Kakamega County. The target population was nurses, medical officers and clinical officers. Data was collected using self-administered questionnaires and a total of 280 healthcare professionals from 7 government hospitals in Kakamega county participated in the study. From these hospitals 221 healthcare professionals (medical officers $=11,5 \%$, nurses $=165,75 \%$ and clinical officers $=71,32 \%)$ completed the questionnaire. Healthcare professionals (HCPs) reported that, they occasionally $(n=75,33.9 \%)$ referred patients to other professionals for fitness assessment or appraisal, they occasionally $(n=78,35.3 \%)$ provided patients with verbal directions for a physical activity program, they very rarely $(n=73,33 \%)$ provided patients with written directions for a physical activity program, they frequently ( $\mathrm{n}=7132.1 \%$ ) counselled PA (verbal or written prescription) for purposes of preventing chronic disease, they occasionally $(n=76,34.4 \%)$ discussed about physical activity with their patients and 59 (26.7\%) very rarely participated in exercise session at least three times a week. The independent between- group ANOVA yielded a non- statistically significantly effect, $F(2,218)=1.132, p=.324, \eta_{p}{ }^{2}=.01$. Statistical power was not adequate and was equal to .248. Thus, the null hypothesis of no significant differences in knowledge of exercise prescription in health professionals at public health facilities in Kakamega was accepted. In conclusion these findings lend support for further training, increased incorporation, and further growth needed in healthcare professionals' self-efficacy in the prescription of exercise.
\end{abstract}

Keywords: physical activity prescription/counseling, non-communicable diseases, healthcare professionals, kenya, health promotion, healthcare setting, primary care, preventive health

Cite This Article: Oloo Micky Olutende, Peter Wisiuba Bukhala, and Bernard Wesonga, "Exercise Prescription: Practices of Healthcare Professionals in Hospital Setting, Kenya.” Journal of Physical Activity Research, vol. 3, no. 1 (2018): 47-54. doi: 10.12691/jpar-3-1-8.

\section{Background}

The healthcare setting has been recognized as an appropriate and promising venue for counseling and prescribing physical activity to increase the activity index of the population $[1,2,3,4,5]$. When done adequately, Healthcare Professionals' initiated physical activity (PA) counseling is moderately effective, resulting in short-term (12 months) improvements in patients' physical activity (PA) levels [6]. Research shows that healthcare professionals have access to a large proportion of the sedentary population $[7,8]$ and therefore, physicians have been identified as having a critical role in addressing the prevalence of physical inactivity [9]. Health care professionals(HCPs) have the best opportunity to question and counsel patients about the importance of physical activity as many people go to them for lifestyle advice $[2,3,10]$. They are therefore considered to be well positioned to champion the course of prevention of chronic diseases by prescribing physical activity during standard consultation $[1,4]$

Counseling by physicians and other healthcare professionals (HCPs) has proven to be useful in helping patients improve their lifestyles [6]. However, research shows a gap in practice of exercise prescription [4]. Studies show that despite physical activity (PA) counseling and referral schemes being part of health care systems in the United Kingdom [11], Sweden [12] Switzerland [13] and Brazil [8], rates of PA counseling by physician and other HCPs still remain unacceptably low in countries with available data [2]. 
A recent study conducted on Australian general practitioners (GPs) found the proportion of respondents with high knowledge and confidence in giving physical activity advice has failed to increase over the last seven years, despite several education initiatives conducted during this period [14]. Gnanendran, Pyne, Fallon, \& Fricker [15] found out that majority of physicians said they sometimes $(17 \%)$ or often (51\%) discuss physical activity with patients. In Mexican health care setting [16] found that approximately $48 \%$ of physicians reported that they always ask patients about their physical activity levels. A study done by [17] found that only one-fourth of the doctors (25.3\%) 'always asked and advised' their patients regarding physical activity (PA). With similar findings was a study done by [18] among Canadian primary physicians, where only $26.2 \%$ assessed patient fitness as part of a physical examination or through a fitness test.

In Africa, a study done in Ethiopia by Teferi et al., [4] indicated that most of (Health Care Professionals) HCPs (84.62 \%) did not routinely counsel patients to accumulate 30 minutes of moderate intensity PA on most days of the week and only few (15.38 \%) of HCPs routinely counselled patients on physical activity. This study was consistent with a study done by [19] among South African doctors $(n=315)$, the results showed that only $24.1 \%$ of doctors prescribe exercise as routine.

A review done by (Lobelo \& de Quevedo, 2016) found out that the rates of PA counseling by health care professionals in studies published before 2000 were higher, ranging from $40 \%$ to $70 \%$, compared to studies published after the year 2000 (12\% to $40 \%)$. To try to answer this predicament, Lobelo \& de Quevedo, [2] found several enabling factors for HCPs to counsel patients on PA and these factors were consistent among physicians and non-physicians. These factors included higher patient level of education, being a female HCP, primary care specialty, and in some cases provider's age $>35$ years [2]. With regard to physicians' specialty, studies evaluating family practitioners, pediatricians, geriatricians, and internists, $[20,21,22,23]$ found the same positive association between personal physical activity (PA) habits and exercise counseling among their patients. Lobelo \& de Quevedo, [2] found out that non-physicians especially nurses and social workers, included regular preventive counseling recommendations into their practice more frequently than physicians.

Studies have proposed that physically active healthcare professionals (HCPs) will be more sensitive to the obstacles to starting or maintaining an active lifestyle and, therefore, may have higher success in initiating and sustaining counseling for their own patients on this topic. [17,24,25,26]. Esposito \& Fitzpatrick [27] found a significant correlation between registered nurses' PA habits and increased PA counseling among their patients ( $R=$. 20, $P=.03$ ). These results were consistent with results from a study done by Frank et al., [28], where first-year medical students who reported more vigorous exercise had a more positive attitude toward counseling for exercise in their future practice. Students were followed-up for 4 years and it was found that those who complied with the PA guidelines were more likely to rate exercise counseling as important $(P=.04)$.
A review by Lobelo \& de Quevedo, [2] found only 2 studies from low- and middle-income countries, India and Colombia, and recommended further research in these settings, where $80 \%$ of the deaths due to inactivity and related NCDs occur. This recommendation has not been investigated in Kenya creating a research gap for this proposed study. Therefore, the purpose of this study is to assess healthcare professionals' PA prescription/counseling practices among healthcare professionals in hospital setting.

\section{Methods}

The study was conducted in Kakamega county and ethics approval was obtained from Masinde Muliro University of Science and Technology ethics board, National commission for science and technology, the Kakamega county commissioner and from Kakamega county referral hospital (KCRH). No further approval was needed since the project did not require access to patients or personal data.

\subsection{Research Design}

The study design was a descriptive cross-sectional, that utilized quantitative method. The design was chosen because the data to be collected on exercise counselling behavior was a product of temporal and spacial factors. This particular design was ideal since the research entailed collecting and comparing data from the phenomena at the same time of study. Kothari [29] describes descriptive surveys as formalized and typically structured fact-finding enquiries, involving asking questions (often in the form of a questionnaire) to a group of individuals, adding that the major purpose is description of the current state of affairs as it exists at present and describe "what exists" with respect to variables or conditions in a situation. Therefore, the descriptive survey was deemed the best strategy to fulfill the objectives of this study. Several studies on exercise counselling behavior have found the design robust $[4,16,19]$. The study was not expected to measure changes in exercise counselling behavior at different points in time, further logistical and time issues also influenced the design choice.

\subsection{Study Setting}

The study was conducted in Kakamega County, located in Western Kenya. Kakamega County has 132 government run health facilities ranging from a County Referral hospital to a dispensary distributed in six districts: Kakamega North (Malava), Kakamega Central (Lurambi), Kakamega South (Ikolomani), Kakamega East (Shinyalu) and Butere/Mumias. Numerous private and faith-based facilities also provide health care services to the population in this County. The choice of Kakamega County is based on the fact that it is the second most populous County in Kenya but with a nurse patient ratio of 86.37 per 100,000 people, which is 34.87 per 100,000 people higher than the national average of 51.5 per 100,000 people (Kenya Nursing Workforce Report [MoH], 2012); this means that health professionals in this county 
have an opportunity to meet many sedentary people from the population. Health care professionals (HCPs) working in seven (7) health facilities will be studied. These facilities were four (4) Sub-County hospitals, two (2) County hospitals and one (1) County referral hospital. The County referral hospital, two County hospitals and four Sub-County hospitals were purposively selected because these facilities have higher service availability and readiness assessment index (Government of Kenya [GoK], 2014).

\subsection{Participants}

The study population (280) were nurses, doctors and clinical officers working in public hospitals in Kakamega County. In 2010, the US Preventive Services Task Force (USPSTF) found out that counseling by nurses, doctors or clinical officer increased participants' selfreported PA levels, by approximately 38 minutes per week, in randomized controlled trials (RCT). In addition, Grimstvedt \& Der Ananian [30] found out that research that has been conducted utilizing nurses to deliver health promotion interventions to patients in primary care have been successful, this influenced choice of the study population. Stratified random sampling was embraced to divide the population into homogeneous subgroups as per the professional cadres then simple random in proportion to their number in the population was done. Formulae that was used for calculating the sample size was Cochran [31] with an attrition rate of $10 \%$, since the sample size was less than 10,000 people, the sample size was adjusted with the Finite population correction for proportions based on the populations of nurses $(\mathrm{N}=429)$, doctors $(\mathrm{N}=59)$ and clinical officers $(\mathrm{N}=106)$. There was limited data on the prevalence of exercise counselling and prescription in Kenya. Therefore, for estimation of prevalence the researcher conducted a pilot study in Navakholo sub county hospital and found an estimated assumed prevalence of $50 \%$ on the outcome variable practice of exercise prescription. In addition, an a priori power analysis, using the software application G*Power 3.1 for Windows [32], demonstrated that a sample size of 280 was sufficient in order to discover significant effect sizes.

$$
\begin{gathered}
\boldsymbol{n}_{\boldsymbol{o}}=\frac{\mathbf{z}^{2} \boldsymbol{p q}}{\boldsymbol{e}^{2}} \\
\boldsymbol{n}_{\boldsymbol{o}}=\frac{\left(1.96^{2}\right)(0.5)(0.5)}{0.05^{2}} \\
\boldsymbol{n}_{\boldsymbol{o}}=384+(10 \% \text { attrition })=422 .
\end{gathered}
$$

Since the target population was less than 10,000, the sample size was adjusted using the following formula.

Finite Population Correction For Proportions

$$
\begin{gathered}
n=\frac{\boldsymbol{n}_{\boldsymbol{o}}}{1+\frac{\left(\boldsymbol{n}_{\boldsymbol{o}}-1\right)}{\boldsymbol{N}}} \\
\boldsymbol{n}(\text { nurses })=\frac{422}{1+\frac{(422-1)}{429}}=211,
\end{gathered}
$$

$$
\begin{gathered}
n(\text { doctors })=\frac{422}{1+\frac{(422-1)}{59}}=53, \\
n(\text { clinical officers })=\frac{422}{1+\frac{(422-1)}{106}}=84 .
\end{gathered}
$$

After proportional calculation per health facility the total $n=280, Z=1.96, P=0.5$ (for maximum variability), $e=0.05$ (5\% margin of error), $n_{0}=$ estimate population sample, $N=$ actual population, $n=$ desired sample size.

\subsection{Questionnaire}

The data was collected using a pre-coded self-administered questionnaire. The physical activity prescription/counseling for their patients were measured by using a scale employed questionnaire of physical activity in the National Family Physician Workforce Survey of Canada (NFWSC; 2010) and was also used by Teferi et al., [4]. Participants were not compensated for their willingness to participate. In section one, the information that was collected was demographics characteristics and included age, gender, years of experience, education level and professional cadre. In section two, questions sought to establish exercise prescription practice levels, exercise prescription practice score was computed from ten questions that were asked and measured on a on a 5-point likert scale with the lowest being never $=1$ to very frequently $=5$. To increase the validity and reliability of the instruments, the questionnaire was evaluated by experts. Then based on the feedback the final questionnaire was prepared for pilot study. The pilot study was conducted in Navakholo sub-county hospital. The reliability of the scale of the 10 items was found to be: Internal consistency $=$ (Cronbach's $\alpha=0.840)$.

\subsection{Data Analysis}

Data analysis was done using the statistical program for social sciences (SPSS) version 22. Inferential and descriptive statistics were used to analyze data. Descriptive analysis of data was done using the mean, frequencies and percentages. In this study association between the study variables was assessed by a two-tailed probability value of $\mathrm{p}<0.05$ for significance. Schlomer et al. [33] outlined guidelines for best practices regarding the handling and reporting of missing data within research. Visual inspection of the data illustrated that missing data appeared to be missing at random. After visual inspection, in order to further examine the pattern of missing data, the researcher evaluated whether the data was missing completely at random (MCAR). The researcher utilized Little's MCAR test [33] which employs a chi-square statistical analysis and assumes the null hypothesis, that missing data is missing completely due to randomness. In this case, failing to reject the null hypothesis indicates that the data was most likely not missing in a random way. For this study, Little's MCAR test results showed that Practice $\left(\chi^{2}[112]=86.447, p=.965\right)$ was not significant indicating that the variables were missing completely at random, the researcher proceeded to address the missing data. To 
avoid reducing the variances of the scores by replacing missing items using subscale means, the missing data items were instead imputed using the Expectation- Maximization (EM) algorithm within SPSS 23; EM is considered a superior method for conducting missing data imputation when one has MCAR data [33]. Their guidelines were considered when reviewing the missing data for the current research study. The data was tested for assumptions of normality using the Shapiro Wilk test, Skewness and Kurtosis were also checked. Homogeneity of variance was checked using the Levene test. All assumption for conducting the above parametric tests were met before undertaking the test. ANOVA was used to determine if healthcare providers differed with regards to knowledge of exercise prescription. In case of observing significant differences Hochberg's GT2 post-hoc test was used. Alpha level for all the computations was considered $\mathrm{p}<0.05$.

\section{Results}

The study asked the respondents to indicate their background characteristics based on the position they held at the hospital, gender, highest education level, age bracket and working experience. The summary of their responses is given in Table 1.

Firstly, the respondents were asked if they ask patients about their physical activity levels. The results in Figure 1 below showed that, of the 221 respondents, majority $(n=105,47.5 \%)$ said that they occasionally asked patients about their physical activity levels, majority $(n=81,36.7 \%)$ said that they occasionally assessed patients as part of a physical exam or through a fitness test. The results also showed that majority $(n=75,33.9 \%)$ said that they occasionally referred patients to other professionals for fitness assessment or appraisal, majority $(n=78,35.3 \%)$ said that they occasionally provided patients with verbal directions for a physical activity program. In addition, majority ( $n=73,33 \%)$ said that they very rarely provided patients with written directions for a physical activity program. Results also showed that, majority ( $n=7132.1 \%)$ said that they frequently counselled PA (verbal or written prescription) for purposes of preventing chronic disease. Of the 221 respondents, 76 (34.4\%) said that they occasionally discussed about physical activity with their patients, 71 (32.1\%) indicated that they frequently discussed, 32 (14.5\%) very rarely discussed, a handful very frequently counselled $(n=24,10.9 \%)$ and a few never counselled ( $n=18,8.1 \%$ ). The researcher also wanted to find out how often healthcare professionals participated in exercise session at least 3 times a week. Results showed that, of the 221 respondents majority 59 (26.7\%) said that they very rarely participated in exercise session at least three times a week, 55 (24.9\%) indicated that they occasionally exercised, 49 (22.2\%) said they never exercised, a handful very frequently exercised $(n=35,15.8 \%)$ and a few very frequently exercised $(n=23,10.4 \%)$.

Respondents answered a total of ten closed ended questions. Each response was given a mark based on the level on the 5-point likert scale with the anchors being strongly disagree $=1$ to strongly agree $=5$ and vice versa for questions that were reverse coded. Scale scores were computed by adding responses to the ten questions resulting in a minimum possible score of 10 and a maximum of 45 . The score varied from 10 - 50 points and was classified into 2 levels according to the Blooms' (1956) cut off point as follows:

- Good practice (above $60 \%$ ) 31 or more score

- Poor practice (below 60\%) 30 or less score

From the results, majority of the health care professionals had poor exercise prescription practice 128 (57.9\%) scoring 30 or less, while only 93(42.1\%) had good practice of exercise prescription scoring 31 or more out of the total 45 (Figure 2).

Table 1. Background characteristics of respondents

\begin{tabular}{|c|c|c|c|}
\hline Demographics & & Frequency & Percent \\
\hline \multirow{4}{*}{ Professional cadre } & Doctor & 11 & $5.0 \%$ \\
\hline & Nurse & 187 & $84.6 \%$ \\
\hline & Clinical officers & 23 & $10.4 \%$ \\
\hline & Total & 221 & 100.0 \\
\hline \multirow{3}{*}{ Gender } & Male & 77 & $34.8 \%$ \\
\hline & Female & 144 & $65.2 \%$ \\
\hline & Total & 221 & 100.0 \\
\hline \multirow{4}{*}{ Highest education level } & Diploma & 179 & $81 \%$ \\
\hline & Degree & 39 & $17.6 \%$ \\
\hline & Postgraduate & 3 & $1.4 \%$ \\
\hline & Total & 221 & 100.0 \\
\hline \multirow{5}{*}{ Age bracket } & Below 25 years & 111 & $50.2 \%$ \\
\hline & 26-30 years & 51 & $23.1 \%$ \\
\hline & $31-40$ years & 38 & $17.2 \%$ \\
\hline & Over 41 years & 21 & $9.5 \%$ \\
\hline & Total & 221 & 100.0 \\
\hline \multirow{5}{*}{ Experience } & Less than 5 years & 122 & $55.2 \%$ \\
\hline & $6-10$ years & 71 & $32.1 \%$ \\
\hline & $11-20$ years & 11 & $5.0 \%$ \\
\hline & Over 21 years & 17 & $7.7 \%$ \\
\hline & Total & 221 & 100.0 \\
\hline
\end{tabular}




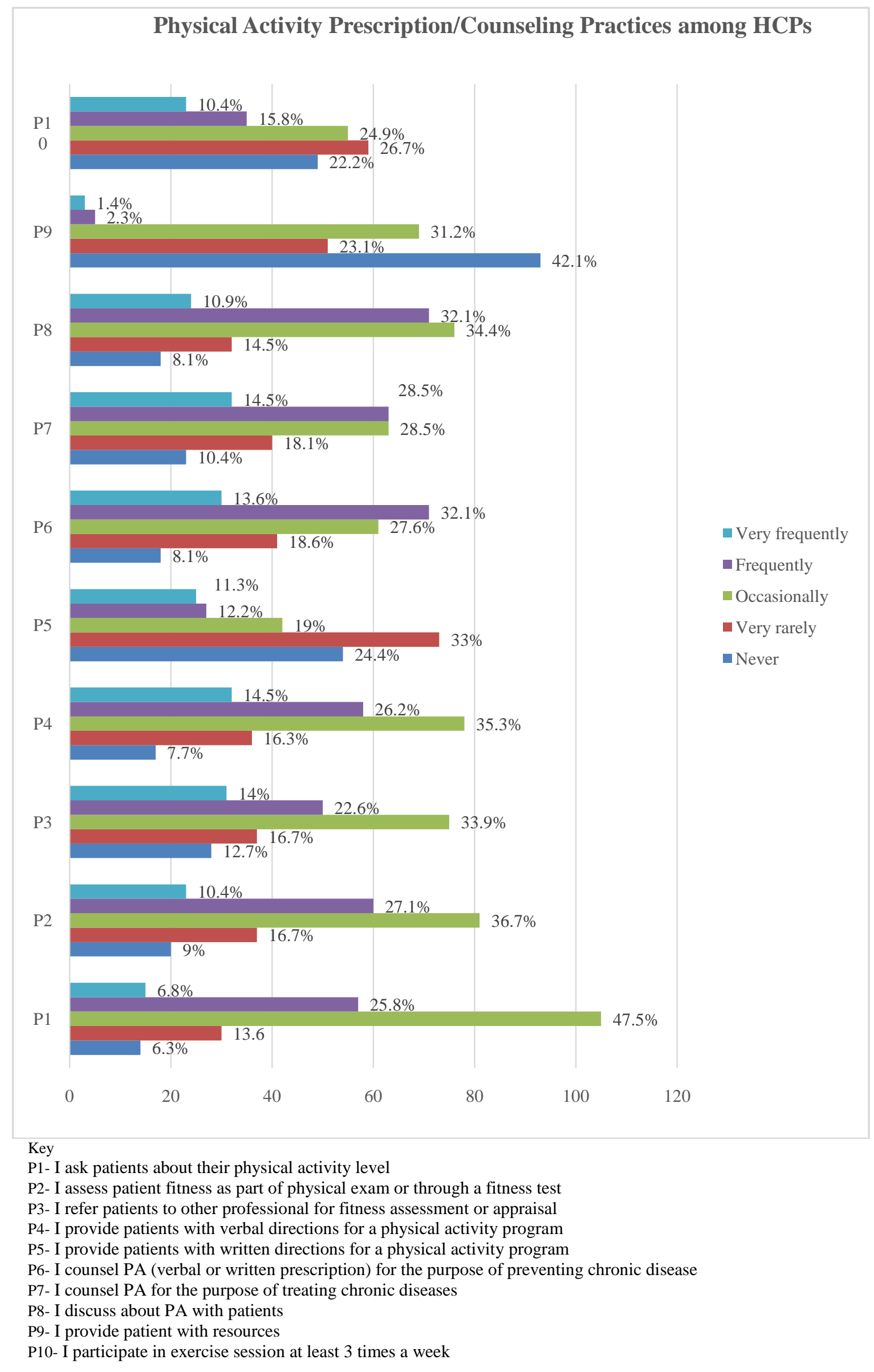

Figure 1. Healthcare professionals' PA prescription/counseling practices 


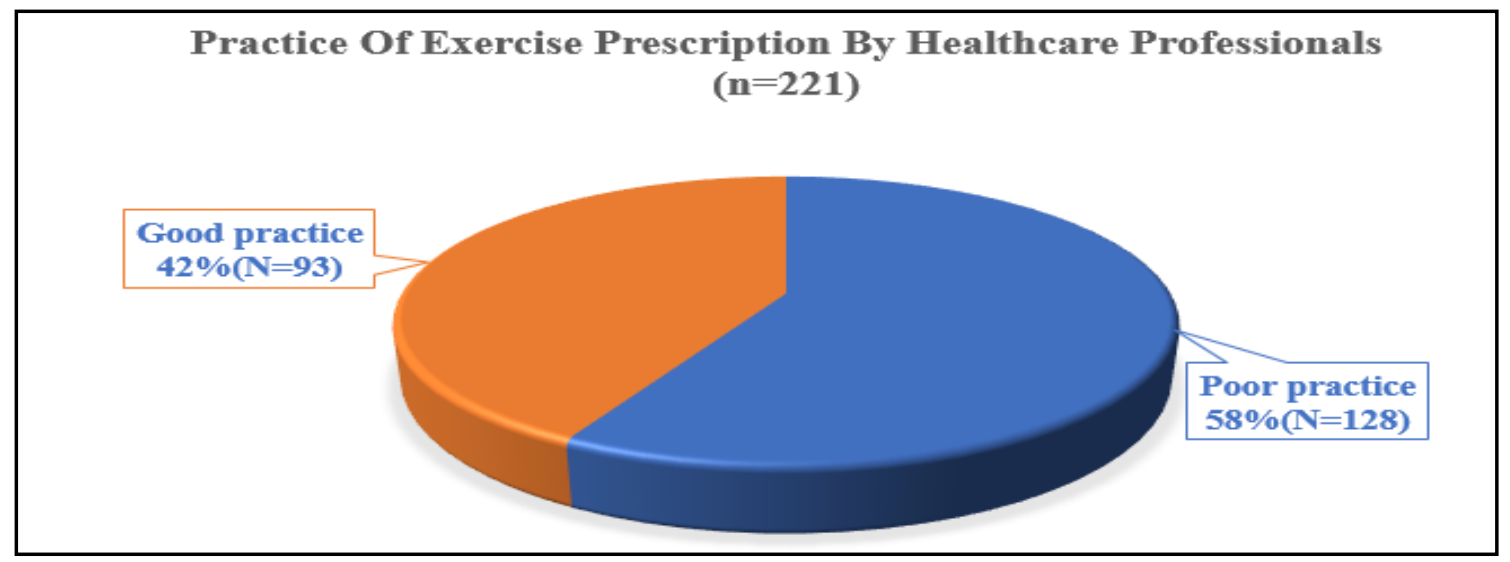

Figure 2. Practice of exercise prescription by Healthcare Professionals

The descriptive statistics associated with practice of exercise prescription across the three health professionals' groups are reported in Table 2. It was seen that the medical officers group was associated with the numerically smallest mean of exercise prescription practice $(\mathrm{M}=29.0 \mathrm{SD}=5.3$ $\mathrm{CI}=25.4-32.6$ ) and nurses group was associated with the numerically highest mean of exercise prescription practice $(\mathrm{M}=29.2 \mathrm{SD}=7.3 \mathrm{CI}=28.1-30.22)$. In order to test the hypothesis that the professional cadre (nurses, clinical officers and medical officers) had an effect on practice of exercise prescription, a between- groups ANOVA was performed.

Prior to conducting the ANOVA, the assumption of normality was evaluated and determined to be satisfied as the three groups distributions were associated with skew and kurtosis less than $|-1.0|$ and $|1.0|$ respectively (see Table 2). Furthermore, the assumption of homogeneity of variances was tested and satisfied based on Levene's F test, $\mathrm{F}$ test $(2,218)=.326, p=.722$.

The independent between- group ANOVA yielded a non- statistically significantly effect, $F(2,218)=1.132$, $p=.324, \eta_{p}^{2}=.01$. Statistical power was not adequate and was equal to .248. Thus, the null hypothesis of no significant differences in practice of exercise prescription in health professionals at public health facilities in Kakamega was accepted, and only $1 \%$ of variance in practice was accounted for by group membership.

Table 2. Descriptive statistics for practice scores across professional cadre

\begin{tabular}{|c|c|c|c|c|c|c|}
\hline Professional cadre & $\mathrm{n}$ & M & SD & CI 95\% & Skewness & Kurtosis \\
\hline nurse & 187 & 29.2 & 7.3 & 28.1-30.2 & .067 & -.048 \\
\hline medical officer & 11 & 29.0 & 5.4 & 25.4-32.6 & -.546 & -.880 \\
\hline clinical officer & 23 & 31.6 & 7.6 & 28.3-34.9 & -.144 & .589 \\
\hline
\end{tabular}

Note. $\mathrm{M}=$ mean; $\mathrm{SD}$ = standard deviation; $\mathrm{CI}$ = confidence interval

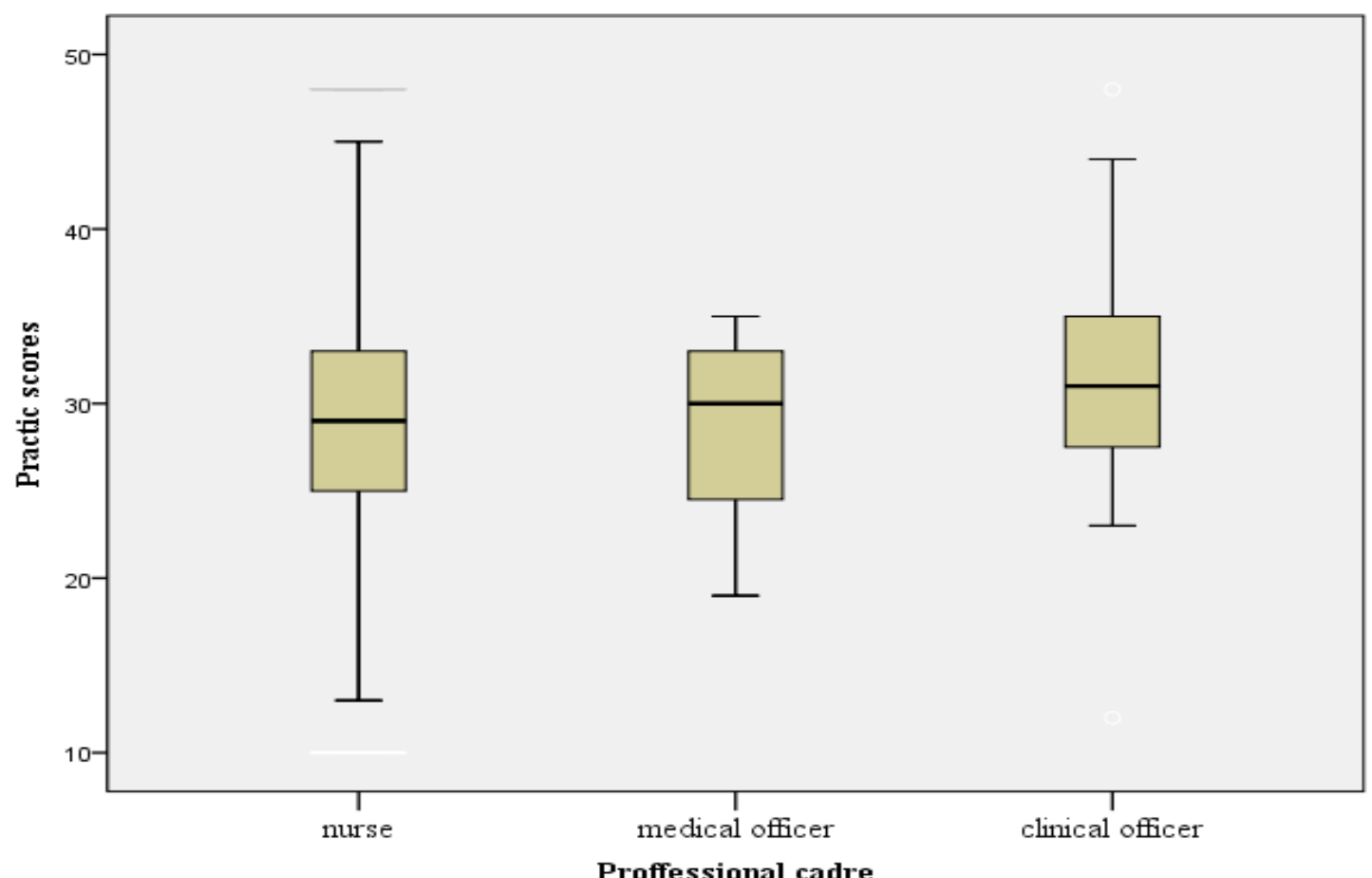

Figure 3. Box plot for practice of exercise prescription by Healthcare Professionals 
The null hypothesis was accepted $(\mathrm{p}>0.05)$ leading to the conclusion that there exist no significant differences in practice of exercise prescription amongst healthcare professionals in Kakamega County, Kenya. Figure 3 below shows the box and whisker plots for the three health professionals. From the figure, the medians were not significantly different, and nurses had the highest score on practice followed by clinical officers then medical officers.

\section{Discussion}

The objective of the study was to find out exercise prescription practice levels amongst healthcare professionals in Kakamega county. As previous studies noted, almost half of healthcare professionals always asked their patients about their physical activity levels [16,18,34]. Other studies noted that majority (76.2\%) of healthcare professionals never asked their patients regarding physical activity [4], a study by Petrella, Lattanzio and Overend, [18] also noted that only $26.2 \%$ assessed patient fitness as part of a physical examination or through a fitness test. My study found some evidence to corroborate, at least partially, with some of the previous findings. The current study found out that $47.5 \%$ of the healthcare professionals said that they occasionally asked patients about their physical activity levels.

With regards to exercise counselling and exercise prescription in healthcare setting, previous studies noted, that an average of at least half of the healthcare professionals counsel or prescribe exercise to their patients $[3,16,35]$. Grimstvedt [36] reported 75 per cent of nurses and physician assistants reported that they routinely counselled patients about physical activity. Contrary to this a study done in Ethiopia noted that $60.2 \%$ of healthcare professionals reported that, they never provided written prescription of PA to their patients, in South Africa Roos [19] noted that $79.9 \%$ of healthcare professionals prescribed exercise to their patients. The current study found that $32.1 \%$ of the respondents frequently counselled PA (verbal or written prescription) for purposes of preventing chronic disease. This is consistent with a study done by Bize et al. [37] that found that doctors were more likely to provide counselling if the patient had cardiovascular disease symptoms. This is supported by the findings of Watson et al. [35] which reported that $72 \%$ of GPs will always give advice to patients with hypertension.

Another interesting finding was that $33.9 \%$ of the healthcare professionals occasionally referred patients to other professionals for fitness assessment or appraisal. These results were consistent with a study done by Teferi, Kumar, \& Singh [4] that found $27.9 \%$ of healthcare professionals occasionally refers patients to other fitness experts. Results from a study done by Galaviz et al, [16] were also consistent although the proportions were slightly lower with $8 \%$ of the practitioners referring patients to fitness experts.

In the last decade, several studies have found that approximately a half of practitioners are themselves actively engaged in regular physical exercise [4,24,34]. Studies have noted that practitioners' own exercise habits have a significant impact on exercise prescription and that higher reports of exercise predict higher probabilities of prescribing exercise to patients $[4,17,24,27,28]$. The study found some evidence to corroborate, at least partially, with some of the previous findings. In the current sample, only $26.7 \%$ of the participants reported they rarely participated in exercise sessions at least three times a week. These findings are consistent with the WHO/ACSM physical activity recommendations. As such, we can assume that healthcare professionals are projecting their own motives and values of exercise onto their patients.

\section{Conclusion \& Recommendation}

This study design utilized a simple yet direct approach to survey the practices of exercise prescription by healthcare professionals. Despite the low rates of prescribing $\mathrm{PA}$, for purposes of preventing and treating chronic diseases, there is need for improved implementation to establish strategies to increases HCPs' practice of PA prescription/counseling in hospital setting. Future studies could attempt to survey a greater number of healthcare professionals, as well as those from other countries, in order to observe cultural similarities and differences. This in turn could help us identify how Kenyan healthcare professionals compare to those of other locations; maybe there are philosophical and or concrete training differences when conducting and engaging in exercise prescription. Also, future researchers could work alongside in order to create a more robust measure of exercise prescription in healthcare setting, which can be used by more researchers. Future naturalistic and randomized clinical trial studies that evaluate the impact of exercise prescription on patients' outcomes need to be done. One would expect to see individual differences between patients who worked with healthcare professionals who prescribe exercise, versus patients who worked with practitioners who did not prescribe exercise.

\section{References}

[1] Matheson, G. O., Klugl, M., Dvorak, J., Engebretsen, L., Meeuwisse, W. H., Schwellnus, M., ․ \& Weiler, R. (2011). Responsibility of sport and exercise medicine in preventing and managing chronic disease: applying our knowledge and skill is overdue. Br J Sports Med, 45(16), 1272-1282.

[2] Lobelo, F., \& de Quevedo, I. G. (2016). The Evidence in Support of Physicians and Health Care Providers as Physical Activity Role Models. American Journal of Lifestyle Medicine, 10(1), 36-52.

[3] Lamming, L., Pears, S., Mason, D., Morton, K., Bijker, M., Sutton, S., \& Hardeman, W. (2017). What do we know about brief interventions for physical activity that could be delivered in primary care consultations? A systematic review of reviews. Preventive Medicine, 99, 152-163.

[4] Teferi, G., Kumar, H., \& Singh, P. (2017). Physical Activity Prescription for Non-Communicable Diseases: Practices of Healthcare Professionals in Hospital Setting, Ethiopia. IOSR Journal of Sports and Physical Education, 4(1), 54-60.

[5] Leemrijse, C. J., de Bakker, D. H., Ooms, L., \& Veenhof, C. (2015). Collaboration of general practitioners and exercise providers in promotion of physical activity a written survey among general practitioners. BMC Family Practice, 16(1), 96.

[6] Orrow, G., Kinmonth, A.L., Sanderson, S., \& Sutton, S. (2012). Effectiveness of physical activity promotion based in primary care: systematic review and meta-analysis of randomized controlled trials. BMJ, 344, e1389. 
[7] Vuori, I.M., Lavie, C.J., \& Blair, S.N. (2013). Physical Activity Promotion in the Health Care System. Mayo Clin Proc, 88(12): 1446-61.

[8] Malta, D.C., \& Barbosa da Silva, J. (2012). Policies to promote physical activity in Brazil. Lancet, 380, 195-196.

[9] Weiler, R., Murray, A. \& Joy, E. (2013). Do all health care professionals have a responsibility to prescribe and promote regular physical activity: or let us carry on doing nothing. Curr Sports Med Rep, (12), 272-275.

[10] O’ Brien, M. W., Shields, C. A., Oh, P. I., \& Fowles, J. R. (2017). Health care provider confidence and exercise prescription practices of Exercise is Medicine Canada workshop attendees. Applied Physiology, Nutrition, and Metabolism, 42(4), 384-390.

[11] Murphy, S.M., Edwards, R.T., ........\& Williams, N. (2012). An evaluation of the effectiveness and cost effectiveness of the National Exercise Referral Scheme in Wales, UK: a randomized controlled trial of a public health policy initiative. $J$ Epidemiol Community Health, 66, 745-753.

[12] Leijon, M.E., Bendtsen, P., Nilsen, P., Ekberg, K., \& Ståhle, A. (2008). Physical activity referrals in Swedish primary health careprescriber and patient characteristics, reasons for prescriptions, and prescribed activities. BMC Health Serv Res, 8, 201.

[13] Wanner, M., Martin-Diener, E., Bauer, G.F., Stamm, H., \& Martin, B.W. (2011). Allez Hop, a nationwide programme for the promotion of physical activity in Switzerland: what is the evidence for a population impact after one decade of implementation? $\mathrm{Br} J$ Sports Med, 45, 1202-1207.

[14] Buffart, L.M., van Der Poleg, H.P., Smith, B.J., Kurko, J., King, L., \& Bauman, A.E. (2009). General practitioners' perceptions and praces of physical activity counselling: changes over the past 10 years. British Journal of Sports Medicine, 43, 1149-1153.

[15] Gnanendran, A., Pyne, D. B., Fallon, K. E., \& Fricker, P. A. (2011). Attitudes of medical students, clinicians and sports scientists towards exercise counseling. Journal of Sports Science and Medicine, 10(3), 426-431.

[16] Galaviz, K.I., Jauregui, E., Fabrigar, L., Latimer-Cheung, A., Lopez, y., Taylor, J., \& Lévesque, L (2015). Physical activity prescription among Mexican physicians: a structural equation analysis of the theory of planned behavior. International Journal of Clinical Practice,69(3) 375-383.

[17] Patra, L., Mini, G. K., Mathews, E., \& Thankappan, K. R. (2013). Doctors' self-reported physical activity, their counselling practices and their correlates in urban Trivandrum, South India: should a full-service doctor be a physically active doctor? Br J Sports Med 2015, 49, 413-41.

[18] Petrella, R.J., Lattanzio, C.N., Overend, T.J. (2007). Physical activity counseling and prescription among Canadian primary care physicians. Arch Intern Med, 167, 1774-81.

[19] Roos, M. G. (2014). Exercise Prescription: Knowledge , Practice and Attitudes, Among South African Doctors, (July). Retrieved from

http://scholar.ufs.ac.za:8080/xmlui/bitstream/handle/11660/1759/ RoosMG.pdf?sequence=1 accessed 02/05/16.

[20] Abramson, S., Stein, J., Schaufele, M., Frates, E., \& Rogan, S. (2000). Personal exercise habits and counseling practices of primary care physicians: a national survey. Clinical Journal of Sport Medicine: Official Journal of the Canadian Academy of Sport Medicine, 10(1), 40-48.

[21] Lewis, C., Wells, K., \& Ware, J.E. (1986). A model for predicting the counseling practices of physicians. J Gen Intern Med, 1, 154.

[22] Livaudais, J.C., Kaplan, C.P., Haas, J.S., Pérez-Stable, E.J., Stewart, S., \& Jarlais, G.D. (2005). Lifestyle behavior counseling for women patients among a sample of California physicians. $J$ Womens Health (Larchmt), 14, 485-495.

[23] Lewis, C.E., Clancy, C., Leake, B., \& Schwartz, J.S. (1991). The counseling practices of internists. Ann Intern Med, 114, 54-58. [PubMed: 1983933].

[24] Banday, A.H., Want, F.A., Alris, F.F.A., Alrayes, M.F., and Alenzi, M.J.A. (2015). Cross-sectional Study on the Prevalence of Physical Activity Among Primary Health Care Physicians in Aljouf Region of Saudi Arabia. Mater Sociomed; 27(4), 263-266.

[25] Joy, E.L., Blair, S.N., McBride, P., \& Sallis, R. (2013). Physical activity counselling in sports medicine: a call to action. $\mathrm{Br} J$ Sports Med, 47, 49-53.

[26] Lobelo, F., Duperly, J., \& Frank, E. (2009). Physical activity habits of doctors and medical students influence their counselling practices. Br J Sports Med, 43(2) ,89-92.

[27] Esposito, E.M., \& Fitzpatrick, J.J. (2011). Registered nurses' beliefs of the benefits of exercise, their exercise behavior and their patient teaching regarding exercise. Int J Nurs Pract, 17, 351-356. [PubMed: 21781214].

[28] Frank, E., Tong, E., Lobelo, F., Carrera, J., \& Duperly, J. (2008). Physical activity levels and counseling practices of U. S. medical students. Medicine \& Science in Sports \& Exercise, 40, 413-421.

[29] Kothari, C. R. (2004). Research methodology: methods \& techniques (Revised 2nd ed.). New Age International (P) Ltd: New Delhi.

[30] Grimstvedt, M., Der Ananian, C., Pasquariello, C. D., Masambia, F. M., Chevan, J., Haskvitz, E. M., ... Rogers, L. Q. (2013). The role of professional counseling associations in professional counseling practice in Kenya. Medicine and Science in Sports and Exercise, 77(3), 200.

[31] Singh, A., \& Masuku, M. (2014). Sampling Techniques \& Determination of Sample Size in Applied Statistics Research: an Overview. Ijecm.Co.Uk, II(11), 1-22.

[32] Erdfelder, E., FAul, F., Buchner, A., \& Lang, A. G. (2009). Statistical power analyses using G*Power 3.1: Tests for correlation and regression analyses. Behavior Research Methods, 41(4), 1149-1160.

[33] Schlomer, G. L., Bauman, S., \& Card, N. A. (2010). Best practices for missing data management in counseling psychology. Journal of Counseling Psychology, 57(1), 1-10.

[34] Bolarinde, O., \& Olagbegi, O. M. (2015). Knowledge , Attitude and Practice of Physical Activity Among Health Professionals in a Nigerian Tertiary. South American Journal of Public Health, 78(2)

[35] Watson, E. D., Khan, T., Crear, C. M. (2013). Do South African general practitioners believe that "Exercise is Medicine"? South African Journal of Sport Medicine, 25, 18-22.

[36] Grimstvedt, M. (2011). Physical activity counseling knowledge, attitudes, and practices among nurse practitioners and physician assistants. (Unpublished doctoral dissertation). Arizona State University, Phoenix, AZ. Retrieved from http://proxy2.hec.ca/login?url=http://search.proquest.com/docview /863480367?accountid=11357\%5Cnhttp://gutenberg.hec.ca:3210/s fxlcl3?url_ver=Z39.88-2004\&rft_val_fmt=info:ofi/fmt:kev:mtx: dissertation\&genre=dissertations+\%26+theses\&sid=ProQ:ProQue st+Disserta.

[37] Bize, R., Cornuz, J., Martin, B. (2007). Opinions and attitudes of a sample of Swiss physicians about physical activity promotion in a primary care setting. Schweizerische Zeitschrift Fur Sportmedizin Und Sporttraumatologie, 55, 97-100. 